\title{
EEN HOOGFIJN SINGHALEES IVOORTJE
}

Op het eiland Sri Lanka waar olifanten inheems zijn en in groten getale voorkomen, werden vanouds olifanten gevangen, getraind en gereed gemaakt voor de handel. De VOC had het monopolie op de vangst en de handel en haalde hier ook de olifanten vandaan die tot diplomatieke geschenken in Azië en Europa dienden. ${ }^{1}$

Ivoor is afkomstig van de slagtanden van olifantenmannetjes, maar niet alle mannetjes hebben slagtanden. Het materiaal is dus zeldzaam en kostbaar. Bij de eerste kennismaking door Europeanen in de $16^{\mathrm{C}}$ eeuw werd het exotische materiaal direct hoog gewaardeerd. In het diplomatieke verkeer tussen de koning van Ceylon en de Portugezen werden een aantal heel bijzondere ivoren kistjes gemaakt met politieke boodschappen. Deze belandden via Habsburgs vorstelijk bezit al vroeg in de Schatzkammer der Residenz in München, het Kunsthistorisches Museum in Wenen en in enkele andere musea. ${ }^{2}$ Dergelijke prachtwerken kwamen nooit, of komen al lang niet meer, in de handel.

De ambachtslieden op Ceylon ontwikkelden een rijk scala aan siermotieven voor allerlei soorten voorwerpen in gebruik door de koning, het hof, voor diplomatieke betrekkingen en de boeddhistische kerk: tronen, draagstoelen, waaiers, staatsiewapens, sieraden, benodigdheden voor het betelkauwen, deksels van palmbladmanuscripten, Boeddhabeelden en de omlijsting daarvan en van toegangen tot heiligdommen en voor de jaarlijkse processie van de heilige tand. ${ }^{3}$

In de Rijksmuseumcollectie bevindt zich een aantal Singhalese voorwerpen. Een gouden met edelstenen bezette vingerring behoorde tot de uitrusting van een Singhalese edelman. ${ }^{4}$ Een staatsiemes, en twee staatsiedegens zijn hoogstwaarschijnlijk in 1765 bij de strafexpeditie tegen Kandy uit het paleis meegenomen. ${ }^{5}$ Een siermes met ivoren heft werd in 1937 op een veiling gekocht. ${ }^{6}$ Drie partizanen (staatsielansen) zijn afkomstig uit het wapenrek van de gouverneur-generaal J.C. Baud (1834-1836). ${ }^{7}$ Deze voorwerpen zijn hoogstwaarschijnlijk afkomstig uit de vorstelijke werkplaatsen van Kandy.

In de $17^{\circ}$ en $18^{\circ}$ eeuw, toen de VOC grote invloed had op Ceylon, was er zoveel vraag naar luxe-voorwerpen voor Europeanen dat de Singhalese ivoorsnijders de siermotieven vereenvoudigden en soms mengden met Europese. Ivoren haarkammen die oorspronkelijk een verlovingsgeschenk waren van een Singhalees aan zijn bruid, ${ }^{8}$ werden ook verzamelobjecten voor Europeanen. ${ }^{9}$ Maar nog veel geliefder waren kistjes en kastjes, veelal met zilveren monturen, voor kostbaarheden, benodigdheden voor betelkauwen,

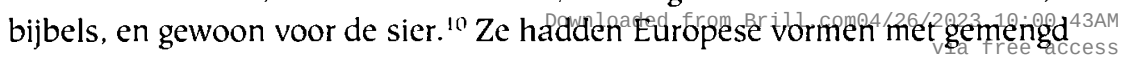




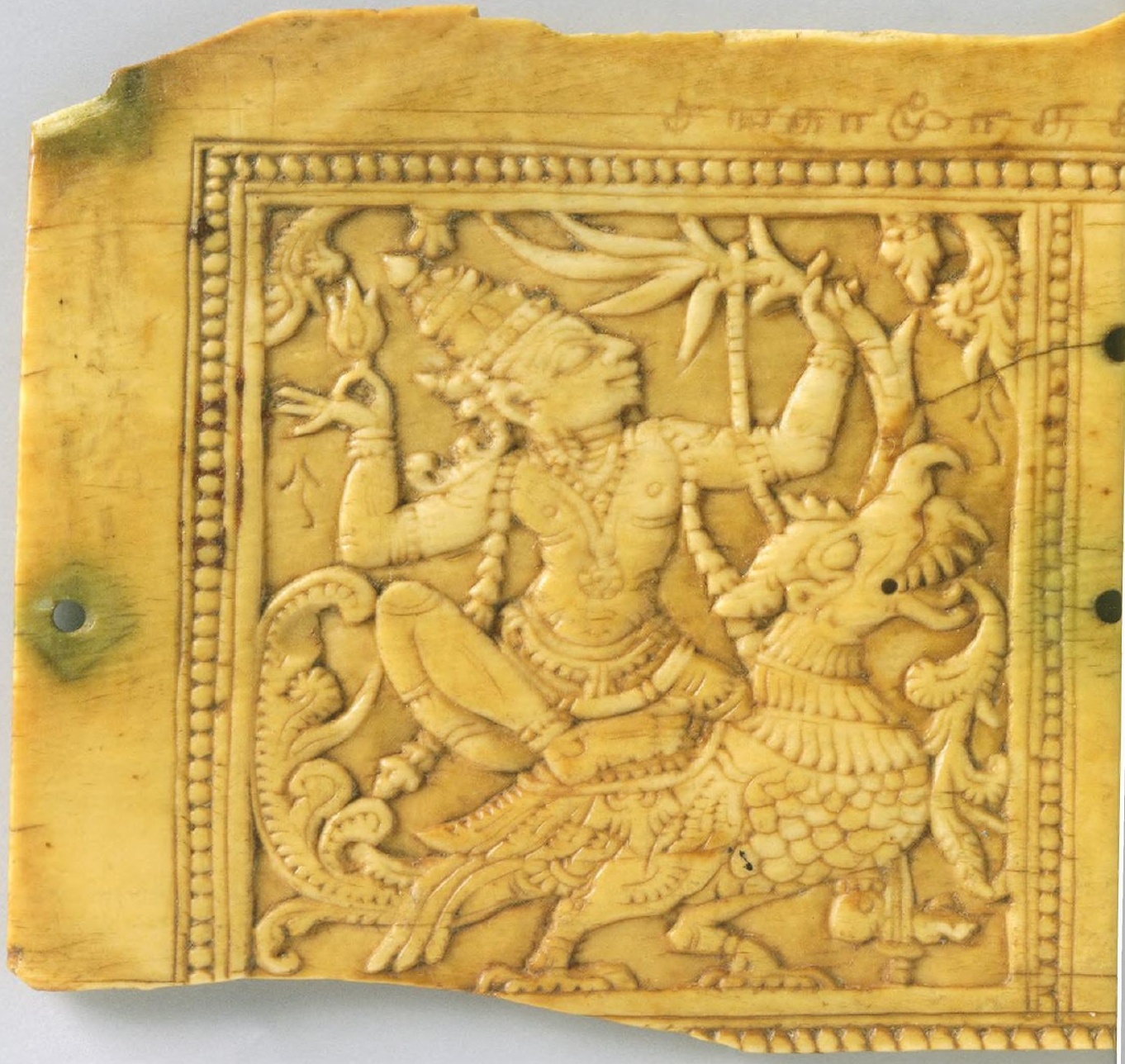

\section{Afbeelding 1}

Ivoren plaatje, $5 \times 12 \mathrm{~cm}$.,

Ceylon, 18 eeuw, AK-MAK-

1730, verworven met steun

van het SNS Reaal Fonds. 


\section{${ }^{2} \cos ^{2}{ }^{2}$}
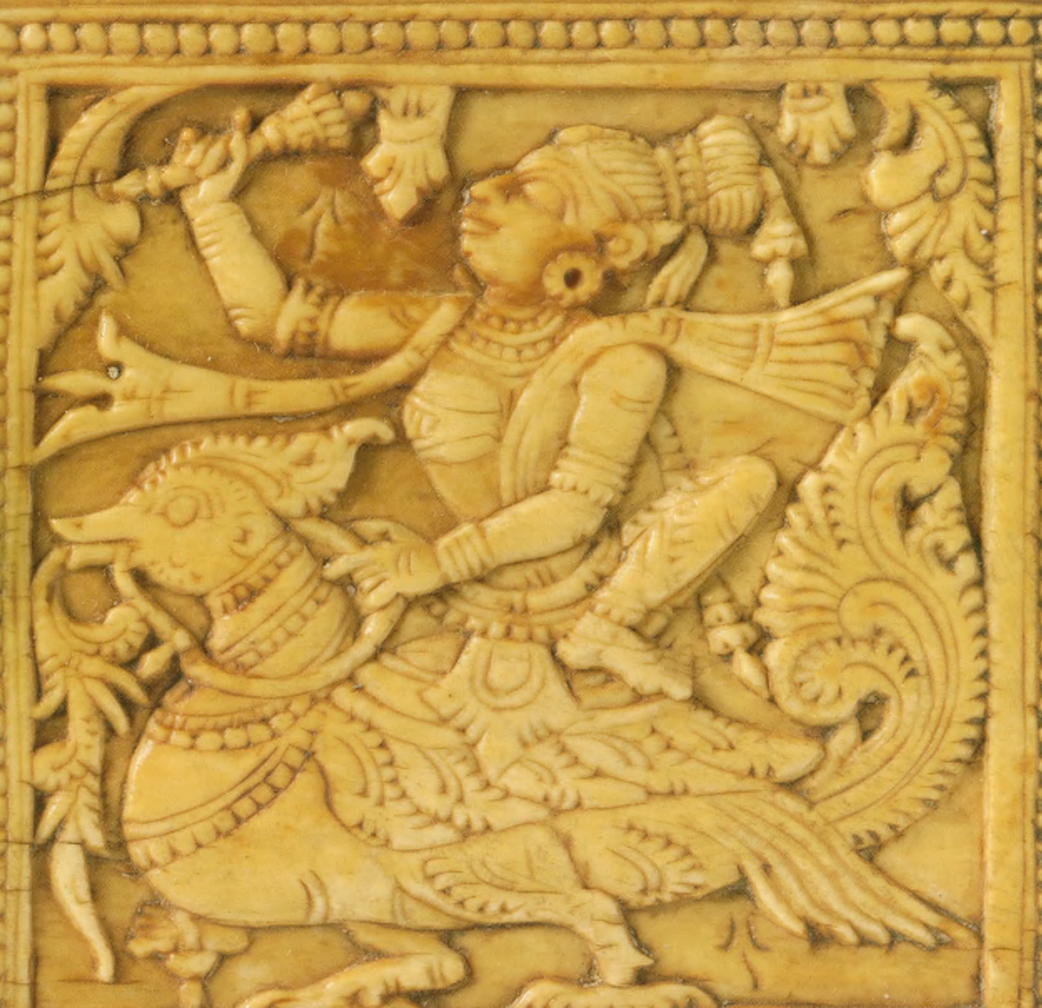
Singhalees-Europese decoraties en werden in een grote variëteit gemaakt. Van dit soort aantrekkelijke kistjes bevindt zich een vijftal in het Rijksmuseum. ${ }^{11}$

Kort geleden is het de VVAK gelukt een zeer fraai en fijn bewerkt $18^{\mathrm{c}}$-eeuws ivoren plaatje uit Ceylon aan de collectie in het Rijksmuseum toe te voegen (afb. 1). Op het oppervlak van slechts $5 \times 12 \mathrm{~cm}$. is het Hindoese godenpaar van de liefde in vol ornaat weergegeven. Ongeveer een centimeter vanaf de buitenranden van het plaatje is een parelrand uitgesneden. Het langwerpige vlak daarbinnen is in tweeën verdeeld. In beide rechthoeken die zo ontstaan zijn, is een godenfiguur in laag reliëf aangebracht. De ivoorsnijder heeft de onderdelen van de figuren zo gebogen en gerangschikt dat het hele vlak op elegante manier ermee gevuld wordt. Beide godheden zitten op hun rijdier: Kama (links), de god van de liefde, op zijn papegaai, en Rati (rechts), godin van seksuele begeerte, op haar gans. Ze zijn in profiel afgebeeld, en naar elkaar toe gewend. Kama is gewapend met een boog van suikerriet en een bloem als pijl.

Midden boven de parelrand is een inscriptie in de Zuid-Indiase taal Tamil aangebracht. Getranscribeerd luidt die: cankaramürttiācāri en vertaald: 'de ācāri Shankaramurtti'. ${ }^{12}$ Het woord ācāri kan, in het Tamil, ofwel 'een leermeester' betekenen - in het Sanskrit: 'ácärya', een term die vooral als titel van priesters en geleerden wordt gebruikt - ofwel kan het de titel zijn van iemand die tot een van de ambachtsliedenkasten behoort. De naam 'Shankaramurtti' zou dus zowel op de naam van de eigenaar van het ivoortje kunnen duiden, als op de maker ervan. Beide gevallen zijn in de ZuidAziatische kunst ontzettend zeldzaam en dit maakt ons ivoortje wel erg bijzonder.

In de verticale baan tussen de twee rechthoeken van het ivoren plaatje zijn boven elkaar twee gaten geboord; ook twee gaten in de linker- en rechter buitenrand, maar daar bevinden ze zich verder van elkaar.

Het plaatje is waarschijnlijk een deel van een kistje. Het is te dik om als beslag gediend te hebben. Een compleet kistje met een dergelijke versiering heb ik niet kunnen vinden. Een oude hindoeïstische traditie schrijft voor dat voorafgaand aan het samenkomen van man en vrouw, er door beide toilet gemaakt moet worden. ${ }^{13}$ Het lijkt daarom waarschijnlijk dat een dergelijk kistje binnen een hindoeïstisch huwelijk gefunctioneerd heeft. De Tamil inscriptie en de voorstelling wijst niet alleen op vervaardiging, maar ook op functioneren in het noordelijkste puntje van het eiland Sri Lanka, waar sinds onheugelijke tijden een Tamil sprekende hindoeïstische bevolking woont. De goede kwaliteit van het snijwerk, het thema en de inscriptie duiden op een kleine gemeenschap waarin zowel de maker als de klant kennis van zaken hebben.

Het Rijksmuseum blijkt verspreid over de collecties een behoorlijk aantal kunstvoonwerpen uit Sri Lanka te bezitten, die zowel voor de hoogste klant op het eiland zelf, als voor de Europese export binnen en ver buiten het eiland bedoeld waren. Dit plaatje voegt een kunstwerk toe dat binnen de kleine Tamil gemeenschap functioneerde. 
1. Over de olifantenvangst en -handel op Sri Lanka, zie Remco Raben in: Max de Bruijn en Remco Raben (red.), The World of Jan Brandes, 1743-1808, Zwolle en Amsterdam, 2004, pp. 262-299; en een afbeelding op de zijkant van een Singhalees ivoren kistje in Het Machtig Eyland. Ceylon en de V.O.C. (tent.cat.

Scheepvaartmuseum), Amsterdam, 1988, p. 74. Het Singhalese woord, kurunayak, is als 'kornak' in het Nederlands en Portugees het woord voor olifantenbestuurder geworden.

2. Het Victoria and Albert Museum en het British Museum in Londen, het Museum of Fine Arts in Boston en in Portugese collecties, zie Wilfried Seipel (red.), Exotica. Portugals Entdeckungen im Spiegel fürstlicher Kunst- und Wunderkammern der Renaissance, Wenen, 2000; Amin Jaffer and Melanie Anne Schwabe, 'A group of sixteenth-century ivory caskets from Ceylon', Apollo, March 1999, pp. 3-14. Het Rietberg Museum te Zürich organiseert in het najaar van 2010 een tentoonstelling van ivoren voorwerpen gemaakt in opdracht van Portugezen.

3. Zie J.E. van Lohuizen-de Leeuw, Sri Lanka, Ancient Arts (tent.cat. Commonwealth Institute), Londen, 1981, pp. 81-81; U. von Schroeder, Buddhist Sculptures of Sri Lanka, Hong Kong, 1990, pp. 532-549.

4. Pauline Lunsingh Scheurleer, 'Twee Oosterse sieraden uit de stadhouderlijke verzameling,' Bulletin van het Rijksmuseum 44/1 (1996), pp. 15-24.

5. Respectievelijk inv.nrs. NG-NM-7114, NG-NM-7112 en NG-NM-560.

6. Inv.nr. AK-MAK-195, zie Pauline Lunsingh Scheurleer, 'Een pronkmes uit Ceylon', Aziatische Kunst 26/1 (1996), pp. 52-58.

7. Inv.nr. NG-BR-554-D, -E en -F en verg. P.H.D.H. de Silva, Illustrated Guide to the Colombo Museum, Sri Lanka, 1976, nrs. 122 t/m 127.

8. Jayadeva Tilakasiri, 'Ivory Carving of Sri Lanka', Arts of Asia dl. 4/4 (197.4), pp. 42-46, p. 44.

9. Een fragment in het Rijksmuseum uit de collectie Hülsmann (inv. AK-MAK-1690), twee in het Museum Volkenkunde te Leiden (inv.nr. RMV 31 1-2) en een afkomstig uit het Koninklijk Kabinet van Zeldzaamheden (inv.nr. 360-6127) en een in het Zeeuws Museum te Middelburg van voor 1777.

10. Zie Lodewijk Wagenaar, Galle, VOC-vestiging in Ceylon, Amsterdam, 1994, p. 82.

11. Inv.nrs. BK-1994-55, NG-1994-20, BK-1971-39, BK-1970-8, BK-1975-113.

12. Gelezen en vertaald door Malini Persad van de British Library, Dr. Herman Tieken van de Universiteit Leiden en Dr. Anna Slaczka van het Rijksmuseum.

13. Zie Pauline Lunsingh Scheurleer, 'Rich Remains from Social Anthropological Fieldwork in Eighteenth Century India,' Journal of the History of Collections 8/1, 1996, pp. $71-91$. 